\section{Vancomycin and high-level aminoglycoside resistance in Enterococcus species}

\author{
Seyda Ozarslan Kurtgoz, ${ }^{1}$ Burcin Ozer, ${ }^{2}$ \\ Melek Inci, ${ }^{2}$ Nizami Duran, ${ }^{2}$ Erkan Yula ${ }^{3}$ \\ ${ }^{1}$ City Hospital, Turhal, Tokat; \\ ${ }^{2}$ Department of Medical Microbiology, \\ Mustafa Kemal University, School of \\ Medicine, Hatay; ${ }^{3}$ Department of Medical \\ Microbiology, Katip Celebi University, \\ School of Medicine, Izmir, Turkey
}

\section{Abstract}

The aim of the study was to investigate vancomycin and high-level aminoglycoside resistance (HLAR) in Enterococcus species by phenotypic and genotypic methods. A hundred Enterococcus strains were included in the study. Antimicrobial susceptibilities of strains were investigated by automated system, betalactamase production was investigated by nitrocefin disks, vancomycin resistance and HLAR were investigated by gradient diffusion method (GDM) and disk diffusion method, respectively. For detection of vancomycin and high-level gentamicin resistance (HLGR) genes, polymerase chain reaction was used. Teicoplanin linezolid, vancomycin, ampicillin, penicillin are the most susceptible antibiotics and strains were detected not to produce beta lactamase. Vancomycin resistance was detected in ten isolates by automated system and in only five isolates by GDM. Five isolates carrying VanA gene were determined. The ratio of HLGR and high-level streptomycin resistance was found 40 and $63 \%$ respectively. aac ( $\left.6^{\prime}\right)-1 e$ aph (2")-1a gene was detected in $58 \%$ of strains. E. faecium strains were found more resistant to the antibiotics than the other species. Beta lactamase was detected in none of strains. The automated system detected vancomycin resistance in more strains than GDM. Therefore it is concluded that strains, which were detected to be resistant to vancomycin, should be confirmed by GDM. The ratio of VanA gene in strains is consistent with other studies. The HLAR ratio was found in about half of strains. The ratio of $a a c\left(6^{\prime}\right)-1 e-a p h(2$ ')- $1 a$ gene, which is the most reported gene in our country and other countries and one of the HLGR genes investigated in our study, was detected $58 \%$.

\section{Introduction}

Enterococcus species are detected with increasing frequency in the etiology of nosocomial infections. Enterococcus faecalis and Enterococcus faecium are the most common causes among nosocomial urinary tract infections, surgical site infections and bacteraemia and they lead to serious infections such as endocarditis. ${ }^{1}$

Treatment of enterococcal infections is difficult because they are resistant to many antimicrobial agents by intrinsically and some types of these bacteria show multiple drug resistance. The intrinsic penicillin resistance in enterococci is depended on the presence of penicillin-binding protein 5 (PBP-5) enzyme, which shows low binding affinity to beta-lactam antibiotics. Therefore enterococci are resistant to many beta-lactam antibiotics. The other mechanism of resistance to beta-lactam antibiotics is the production of beta-lactamase. Beta-lactamase-producing enterococci are rarely isolated. ${ }^{2}$ Beta lactamase-producing $E$. faecium strain was first identified in 1981 in the United States. ${ }^{3}$

Enterococci develop resistance to aminoglycoside by two different mechanisms. The moderate level of resistance usually develops due to low permeability. This type of resistance can be eliminated by using aminoglycoside with beta lactam group antibiotics, which inhibit cell wall synthesis. High-level resistance (HLR) occurs due to the result of changes in the ribosome binding site of aminoglycosides or the synthesis of enzymes that inactivate aminoglycoside. HLR is often dependent on the production of transferable plasmid-mediated aminoglycoside inactivating enzymes. The most common aminoglycoside-modifying enzyme in enterococci is APH (2")-AAC (6') and this enzyme is encoded by aac $\left(6^{\prime}\right)$ $a p h(2$ ") genes and consists of two enzymes fused together. This enzyme is responsible for resistance to all aminoglycosides except streptomycin. Aminoglycoside-modifying enzymes are mainly responsible from high-level streptomycin resistance. ${ }^{4,5}$ So far detected aminoglycoside resistance genes in enterococci encoding aminoglycoside-modifying enzymes are aac (6')-Ie-aph (2')-Ia, aph(2")-Ib, aph(2')Ic, aph(2')-Id, aph(3')-IIIa, aac(6')-Ii, ant(3')-Ia, ant(4')-Ia, ant( $\left.6^{\prime}\right)$-Ia. The aminoglycoside resistance in enterococci leads to abortion of treatment wherefore this resistance causes elimination of synergistic effect between beta-lactams and aminoglycosides.

As well as, recently major problems have been encountered in the treatment of emerging vancomycin-resistant enterococci (VRE). ${ }^{4}$ New pathogens resistant to vancomycin generally lead to difficulty in treatment because they are also resistant to other antibiotics. Resistance to glycopeptide group antibiotics was first reported in 1988 and then high-level vancomycin-and teicoplanin-resistant strains have spread worldwide. ${ }^{6}$
Correspondence: Burcin Ozer, Department of Medical Microbiology, School of Medicine, Mustafa Kemal University, 31040 Hatay, Turkey. E-mail: burcinozer@yahoo.com

Key words: Enterococcus; beta lactamase; vancomycin; high-level aminoglycoside; resistance.

Acknowledgements: this study was granted by Mustafa Kemal University Scientific Research Projects (BAP $1204 \mathrm{U}$ 0107). The authors declare that they have no conflict of interest. The authors have no financial conflicts of interest. Ethical Approval was given, by Mersin University Ethical Committee.

Contributions: the authors contributed equally.

Conflict of interest: the authors declare no potential conflict of interest.

Received for publication: 2 February 2016.

Revision received: 2 May 2016.

Accepted for publication: 5 May 2016.

This work is licensed under a Creative Commons Attribution NonCommercial 4.0 License (CC BYNC 4.0).

(C) Copyright S. Ozarslan Kurtgoz et al., 2016 Licensee PAGEPress, Italy

Microbiology Research 2016; 7:6441

doi:10.4081/mr.2016.6441

In studies, glycopeptide resistant enterococci have fairly wide geographical spread and both genotypic and phenotypic heterogenity was determined. So far seven-vancomycin resistance phenotype are defined. These are VanA, VanB, VanC, VanD, VanE, VanG, VanL. ${ }^{7}$ VanA and VanB resistance phenotypes have been described in $E$. faecalis and $E$. faecium. VanA resistant strains can be induced and show high-level resistance to vancomycin and teicoplanin.

In this study, the investigation of vancomycin and high-level aminoglycoside resistance (HLAR) in 100 Enterococcus strains isolated from clinical samples (urine, wound, abscess blood) in Microbiology Laboratory of Mustafa Kemal University Hospital between January 2008-August 2011, by phenotypic and genotypic methods was aimed.

\section{Materials and Methods}

A hundred Enterococcus strains were included in the study isolated from clinical samples (urine, wounds, abscess, blood) between January 2008 and August 2011 in Microbiology Laboratory of Mustafa Kemal University Hospital. Staphylococcus aureus ATCC 25923 and Enterococcus faecalis ATCC 29212 were 
used as control strains.

Identification and antimicrobial susceptibility of the strains were determined by Vitek 2 automated system (bioMerieux, Mercy L'Etoile, France). HLAR was investigated by disk diffusion test using gentamicin $(120 \mu \mathrm{g})$ and streptomycin $(300 \mu \mathrm{g})$ disks (Becton Dickinson, Franklin Lakes, NJ, USA). And it was evaluated according to Clinical and Laboratory Standards Institute (CLSI) criteria. ${ }^{8}$ Vancomycin MIC values of the strains were determined by gradient diffusion method (GDM) using E-test strips (BioMerieux, France) and evaluated according to CLSI criteria. $^{8}$ Nitrocefin method and the nitrocefin disks (Becton Dickinson, USA) were used to investigate the presence of the beta-lactamase in the strains.

\section{Investigation of vancomycin and} high-level aminoglycoside genes by polymerase chain reaction

\section{DNA isolation}

Bacterial DNA isolation was performed with commercial DNA extraction kit [High Pure polymerase chain reaction (PCR) Template Preparation Kit (Roche, Basel, Switzerland)] according to manufacturer's directions.

\section{Amplifying of VanA, VanB and Van C genes}

Amplification of VanA, VanB, Van $C$ genes were performed by PCR method, using primers which were reported by Aktas and colleagues, ${ }^{9}$ aac(6')-1e-aph(2')-1a, aph(2")-1b, aph(2')$1 c$, aph(2")-1d genes were performed using primers which were reported by Qu et al. ${ }^{10}$ (Table 1). The PCR amplification was carried out in a total volume of $25 \mu \mathrm{L}$ reaction mixture. The reaction mixture consisted of $2.5 \mu \mathrm{L}$ Taq buffer (10×) (Fermentas, Waltham, MS, USA), $1.5 \mu \mathrm{LgCl}_{2}$ (25 mm) (Fermentas, USA), 0.5 $\mu \mathrm{L}$ dNTP (10 mM) (Fermentas, USA), $0.25 \mu \mathrm{L}$ (50 pmol) of each primer, 0.5 U Taq polymerase (Fermentas, USA) and $2.5 \mu \mathrm{L}$ DNA and brought up to a $25 \mu \mathrm{L}$ final volume with distilled water. All the amplification processes in this study were started with an initial denaturation step $\left(94^{\circ} \mathrm{C}, 5 \mathrm{~min}\right)$. All the PCR reaction in this study consisted of 30 cycles of amplification. The other steps and temperatures were shown in Table 2.

\section{Amplifying the gentamycin resistance genes}

For the amplification of $a a c\left(6^{\prime}\right)-1 e$-aph( $\left(2^{\prime \prime}\right)$ $1 a$, aph(2")-1b and aph(2")-1c, aph(2")-1d genes, $25 \mu \mathrm{L}$ amplification mixture containing 16.6 $\mu \mathrm{L}$ distilled water, $2.5 \mu \mathrm{L}$ 10X PCR buffer, $1.5 \mu \mathrm{L} \mathrm{Mg}{ }_{2} \mathrm{Cl}(25 \mathrm{~mm}), 0.5 \mu \mathrm{L}$ dNTP $(10 \mathrm{~mm})$ mixture, $0.3 \mu \mathrm{L}$ each primer (50 pmol), $0.3 \mathrm{U}$ Taq DNA polymerase (Fermentas, USA), $3 \mu \mathrm{L}$ extracted DNA. The steps of PCR and temperatures were shown in Table 2.

\section{Demonstration of $P C R$ products}

The PCR products were analyzed in a $2 \%$ $(w / v)$ agarose gel in 1X Tris Borate EDTA (TBE) (Wisent, Canada). Ethidium bromide stained DNA amplicons were visualized using a gel imaging system (Wealtec, Dolphin-View, NV, USA). To determine the expected bp lengths, DNA marker with defined molecular weights in the range 100-3000 bp were used.

For the presence of VanA, VanB, Van C genes, 1030, 433, 796 bp genes products, for aac(6')-1e-aph(2')-1a, aph(2")-1b, aph(2")1c, aph(2”)-1d genes, 505, 906, 627, 642 bp genes products were evaluated respectively (Figure 1).

\section{Statistical analysis}

Data were analyzed using Statistical Package for Social Sciences. Comparison for categorical variables was calculated using chisquare test. A P-value $<0.05$ was considered statistically significant.

\section{Results}

In this study, it was determined that Enterococcus strains isolated from the samples most common submitted from Internal Medicine (13\%), Medical Intensive Care (11\%), Surgical Intensive Care Unit (10\%), pediatrics (10\%),

Table 1. Primer sequences used in polymerase chain reaction methods.

\begin{tabular}{|c|c|c|}
\hline Genes & Primers $\left(5^{\prime} \rightarrow 3\right)$ & Product, base pairs \\
\hline $\operatorname{Van} A$ & $\begin{array}{l}\text { CAT GAA TAG AAT AAA AGT TGC AAT A } \\
\text { CCC CTT TAA CGC TAA TAC GAT CAA }\end{array}$ & 1030 \\
\hline $\operatorname{Van} B$ & $\begin{array}{l}\text { GTG ACA AAC CGG AGG CGA GGA } \\
\text { CCG CCA TCC TCC TGC AAA AAA }\end{array}$ & 433 \\
\hline $\operatorname{Van} C$ & GAA AGA CAA CAG GAA GAC CGC & \\
\hline & ATC GCA TCA CAA GCA CCA ATC & 796 \\
\hline $\operatorname{Aac}\left(6^{\prime}\right)-1 e-a p h\left(2^{\prime \prime}\right)-1 a$ & $\begin{array}{l}\text { GAGCAATAAGGGCATACCAAAAATC } \\
\text { CCGTGCATTTGTCTTAAAAAACTGG }\end{array}$ & 505 \\
\hline$A p h(2 ”)-1 b$ & $\begin{array}{l}\text { TATGGATTCATGGTTAACTTGGACGCTGAG } \\
\text { ATTAAGCTTCCTGCTAAAATATAAACATCTCTGCT }\end{array}$ & 906 \\
\hline $\operatorname{Aph}(2 ")-1 c$ & $\begin{array}{l}\text { GAAGTGATGGAAATCCCTTCGTG } \\
\text { GCTCTAACCCTTCAGAAATCCAGTC }\end{array}$ & 627 \\
\hline $\operatorname{Aph}(2 ”)-1 d$ & $\begin{array}{l}\text { GGTGGTTTTTACAGGAATGCCATC } \\
\text { CCCTCTTCATACCAATCCATATAACC }\end{array}$ & 642 \\
\hline
\end{tabular}

Table 2. The steps and temperatures in polymerase chain reaction amplifications.

\begin{tabular}{lcccc} 
Genes & Denaturation & Annealing & DNA chain extension & Final extension \\
VanA, VanB, VanC & $94^{\circ} \mathrm{C}(30 \mathrm{~s})$ & $58^{\circ} \mathrm{C}(30 \mathrm{~s})$ & $72^{\circ} \mathrm{C}(30 \mathrm{~s})$ & $72^{\circ} \mathrm{C}(10 \mathrm{~min})$ \\
aac (6')-le-aph(2”)-1a & $94^{\circ} \mathrm{C}(1 \mathrm{~min})$ & $61^{\circ} \mathrm{C}(1 \mathrm{~min})$ & $72^{\circ} \mathrm{C}(1 \mathrm{~min})$ & $72^{\circ} \mathrm{C}(10 \mathrm{~min})$ \\
\hline aph(2”)-1b & $94^{\circ} \mathrm{C}(1 \mathrm{~min})$ & $55^{\circ} \mathrm{C}(1 \mathrm{~min})$ & $72^{\circ} \mathrm{C}(1 \mathrm{~min})$ & $72^{\circ} \mathrm{C}(10 \mathrm{~min})$ \\
aph(2”)-1c & $94^{\circ} \mathrm{C}(1 \mathrm{~min})$ & $55^{\circ} \mathrm{C}(1 \mathrm{~min})$ & $72^{\circ} \mathrm{C}(1 \mathrm{~min})$ & $72^{\circ} \mathrm{C}(10 \mathrm{~min})$ \\
\hline aph(2”)-1d & $94^{\circ} \mathrm{C}(1 \mathrm{~min})$ & $53.4^{\circ} \mathrm{C}(1 \mathrm{~min})$ & $72^{\circ} \mathrm{C}(1 \mathrm{~min})$ & $72^{\circ} \mathrm{C}(10 \mathrm{~min})$ \\
\hline
\end{tabular}


Infectious Disease (9\%) and Urology (9\%) clinics. It was found that $52 \%$ of the strains isolated from the urine, $30 \%$ from wound, $14 \%$ from blood, $2 \%$ from abscess, $2 \%$ of them were isolated from the peritoneal fluid samples. And 58 of the strains were $E$. faecalis, 38 of them were $E$. faecium and one of them was $E$. gallinorum. There was no beta lactamase production in these strains. The antibiotics to which the strains were the most susceptible in this study were teicoplanin (94\%), linezolid (91\%), vancomycin (90\%), ampicillin (70\%), penicillin (70\%), nitrofurantoin $(65 \%)$, levofloxacin (41\%), tetracycline $(36 \%)$, eryhtromycin (17\%). High-level gentamicin resistance (HLGR) was detected in $40 \%$ of strains, high-level streptomycin resistance (HLSR) was detected in $60 \%$ of strains. E. faecium strains were found more resistant to nitrofurantoin, ampicillin and penicillin and more susceptible to tetracycline than the other strains $(\mathrm{P}<0.001)$. There was no difference between HLSR and HLGR in different species $(\mathrm{P}>0.05)$. On the other hand $E$ faecalis strains were found more susceptible to erytromycin (0.031), nitrofurantoin $(\mathrm{P}<0.001)$, levofloxacin $(\mathrm{P}=0.035)$, linezolid $(\mathrm{P}=0.028)$, teicoplanin $(\mathrm{P}=0.003)$, ampicillin $(\mathrm{P}<0.01)$, penicillin $(\mathrm{P}<0.01)$, HLS $(\mathrm{P}=0.02)$ but more resistant to tetracycline $(\mathrm{P}<0.001)$ than the other strains. MIC range of vancomycin was found from 0,5 to $256 \mu \mathrm{g} / \mathrm{mL}$ by GDM. And $\mathrm{MIC}_{50}$ and $\mathrm{MIC}_{90}$ value of vancomycin were found 1.5 and $3 \mu \mathrm{g} / \mathrm{mL}$ respectively. $\mathrm{MIC}_{50}$ and $\mathrm{MIC}_{90}$ values were in the range of sensivity limits. Ten strains were found resistant to vancomycin by automated system. Eight of these strains were $E$. faecalis and two of them were $E$. faecium. The rate of vancomycin susceptibilities of Enterococcus spp. determined by automated system in this study is shown in Table 3.

The five strains were determined resistant to vancomycin by GDM. All of these strains were $E$. faecium. The rate of vancomycin susceptibilities of Enterococcus spp. determined

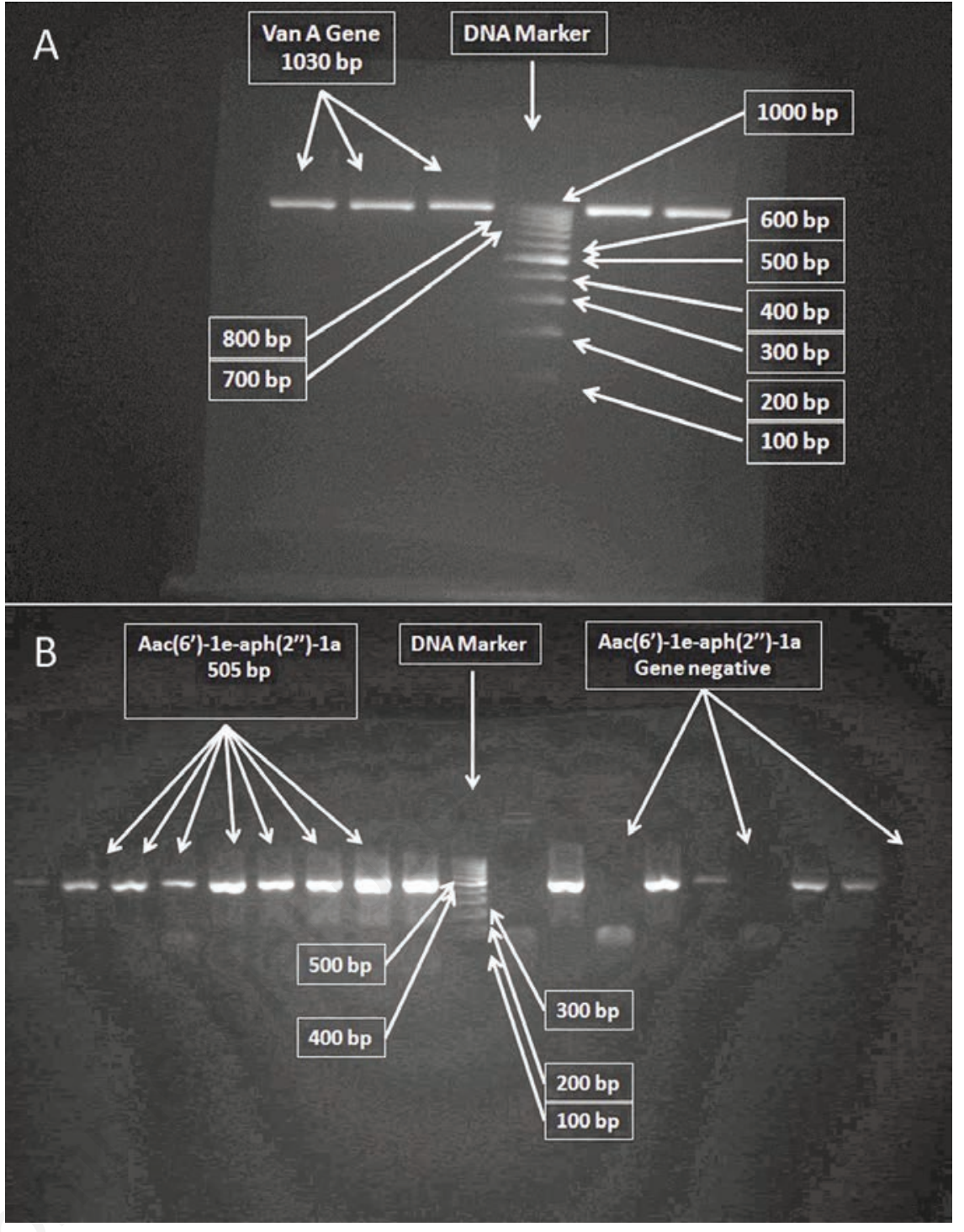

Figure 1. Polymerase chain reaction amplification products of the vanA gene (A) and the aac (6')-1e-aph(2')-1a gene (B).

Table 3. Vancomycin susceptibility of Enterococcus species determined by the automated system.

\begin{tabular}{lcccc} 
Enterococcus species & \multicolumn{2}{c}{ Vancomycin susceptibility } & Total & P \\
& Susceptible, N (\%) & Resistant, $\mathbf{N}(\%)$ & 58 & $>0.05$ \\
E. faecalis & $56(96.5)$ & $2(3.5)$ & 38 & 0.006 \\
E. faecium & $30(78.9)$ & $8(21.1)$ & 4 & $>0.05$ \\
Other & $4(100)$ & $0(0)$ & 100 & \\
Total & $90(90)$ & $10(10)$ &
\end{tabular}

Table 4. Vancomycin susceptibility status of Enterococcus species determined by gradient difusion method.

\begin{tabular}{lccc} 
Enterococcus species & Vancomycin susceptibility & Total \\
& Susceptible, N (\%) & Resistant, N (\%) \\
E. faecalis & $58(100)$ & $0(0)$ & 58 \\
E. faecium & $33(86.4)$ & $5(13.6)$ & 38 \\
\hline Other & $4(100)$ & 0.05 & 4 \\
Total & $95(95)$ & $5(5)$ & 0.007 \\
\hline
\end{tabular}


by GDM in this study is shown in Table 4 .

VanA gene was detected in five strains. Gel image of the five strains containing VanA gene is shown in Figure 1A. VanB and Van $C$ genes were detected in none of the strains (Table 5).

All of the strains carrying VanA gene were $E$. faecium. All of the strains carrying VanA gene were found to be resistant to vancomycin, nitrofurantoin, teicoplanin, ampicillin and penicillin $(\mathrm{P}<0.001)$. MIC values of vancomycin and MIC values of teicoplanin in five VanA positive strains were found higher than MIC values in 95 VanA negative strains $(\mathrm{P}<0.001)$.

aac (6 ')-1-aph (2")-1 gene was detected in 58 strains. aph (2")-1b, aph (2")-1c and aph (2")-1d genes were not detected in the strains. And 4 strains were detected to carry both $a a c\left(6^{\prime}\right)-1 e-a p h(2$ ")-1a gene and VanA gene. HLGR and HLSR were found more frequently in strains carrying $a a c\left(6^{\prime}\right)$-1e-aph (2")-1a gene $(\mathrm{P}<0.001)$ (Table 6).

VanA gene was found in five (5\%) E. faecium. aac (6 ')-1e-aph (2")-1a gene was detected in $22(38 \%)$ E. faecium.

\section{Discussion and Conclusions}

Enterococci are situated between troubled bacteria because of observed in the increasing rate in nosocomial infections and carrying clindamycin, fluoroquinolones, trimethoprimsulfamethoxazole, low level penicillin, lowlevel aminoglycoside and transferring of genetic material or acquired tetracycline, erythromycin, rifampin, chloramphenicol, nitrofurantoin, fusidic acid, and beta-lactam HLAR, fluoroquinolones and vancomycin resistance by mutation. ${ }^{4}$
Initially, the beta-lactamase-producing strains of enterococci were reported as rare in the United States but nowadays isolates all over the world. ${ }^{4}$ In our study, no beta lactamase production was determined. Many studies conducted in our country, beta-lactamase-producing strain did not appear as similar to our study. ${ }^{11,12}$ Beta-lactamase production in enterococci has not been reported in many studies conducted in foreign countries as similar to studies in our country. ${ }^{13,14}$

Partial or complete beta-lactam resistance is characteristic in Enterococcus species. E. faecalis is 10-100 times less susceptible to penicillin than other streptococcal species. E. faecium is 4-16 times less susceptible to penicillin than $E$. faecalis. ${ }^{4}$ In our study, it was determined $30(30 \%)$ of the strains are resistant to ampicillin and penicillin. The strains of $E$. faecalis were more susceptible to ampicillin and penicillin. In our country, Kacmaz and colleagues found that penicillin and ampicillin resistance rates of all strains were respectively 27 and $26 \% .^{11}$ In other countries, D'azevedo and colleagues determined that only 14 strains were high-level ampicillin resistant in their study with 455 enterococci. ${ }^{15}$ In our study, nitofurantoin resistance rate was $35 \%$. In other countries, Moaddab and colleagues found that nitrofurantoin resistance was 1,5\%, Akhtar and colleagues found $5 \%$. 13,16

In our study, tetracycline resistance has been identified in $64 \%$ of strains. The tetracycline resistance rate has been reported as 8.3, $51 \%$ and $70.4 \%$ in some studies. ${ }^{17-19}$

In our study, erythromycin resistance was found to be $69 \%$. Sirin and Adiloglu detected that erythromycin resistance rate was $38 \%{ }^{18}$ Comert and colleagues have found that all of six VRE strains were resistant to erythromycin in their study. ${ }^{20}$ Kirdar and colleagues found that all of 12 VRE strains were resistant to

Table 5. The number of strains containing $\operatorname{Van} A, \operatorname{Van} B, \operatorname{Van} C$ gene.

\begin{tabular}{lccc} 
Genes & Positive, $\mathbf{N}(\%)$ & Negative, $\mathbf{N}(\%)$ & Total \\
Van $A$ & $5(5)$ & $95(95)$ & 100 \\
Van $B$ & $0(0)$ & $100(100)$ & 100 \\
\hline Van $C$ & 0 & $100(100)$ & 100 \\
\hline
\end{tabular}

erythromycin in their study. ${ }^{19}$

Oxazolidinone's are new member of the synthetic antibiotics group with activity against Gram-positive. In our study, linezolid resistance was found to be $7 \%$. Ak and colleagues found that resistance rate for $E$. faecalis was $10.2 \%$, for $E$. faecium was $9.1 \%$ in their study. ${ }^{21}$ These rates were lower in other countries. Akhter and colleagues detected that linezolid resistance rate was $4 \%$ in their study. ${ }^{16}$ Protonotario and colleagues detected that linezolid resistance rate for $E$. faecalis and $E$. faecium were respectively $0.3 \%, 1.6 \%$ in their study. ${ }^{22}$

Enterococcus infections carrying resistance genes against glycopeptides, penicillin and aminoglycoside group of antibiotics lead to serious problems. The number of enterococci strains which are resistant glycopeptide antibiotics such as vancomycin and teicoplanin gradually increase. ${ }^{2}$ Glycopeptide antibiotic resistance in enterococci group was first reported in 1988.6 Then high-level of vancomycin-and teicoplanin-resistant strains has spread all over the world. Efe and colleagues have isolated 21 (18.8\%) VRE strains in 112 patients..$^{23}$ Sirin and Adiloglu determined that all strains were susceptible to vancomycin and teicoplanin except one strain moderately susceptible to vancomycin in 100 enterococci strains in their study. ${ }^{18} \mathrm{Ak}$ and colleagues detected five vancomycin-resistant, one moderately vancomycin resistant strains with automated systems in their study. ${ }^{21}$

In our study, ten vancomycin resistant strains were detected by automated systems, but just five vancomycin resistant strains were identified by GDM. In our country, Karaca and colleagues did not find vancomycin resistance in enterococci by GDM. ${ }^{24}$ Protonotario and colleagues found vancomycin resistance rate of $0.5 \%$ for $E$. faecalis, $9.6 \%$ for $E$. faecium by automated systems in their studies containing 1498 E. faecalis and 625 E. faecium strains. ${ }^{22}$ Zouain and colleagues examined vancomycin and teicoplanin susceptibility of 153 enterococci strains by the disk diffusion and GDM method. The vancomycin or teicoplanin resistance was determined in only one $E$. gallinarum strain, which confers moderate resistance against vancomycin. ${ }^{25}$ Hallgren and colleagues

Table 6. High-level gentamicin resistance (HLGR) and high-level streptomycin resistance (HLSR) rates of strains containing aac(6')$1 e-\operatorname{aph}(2 ")-1 a$ gene.

\begin{tabular}{|c|c|c|c|c|c|}
\hline \multirow[t]{2}{*}{ Antibiotics } & \multirow[t]{2}{*}{ Susceptibility status } & \multicolumn{2}{|c|}{$\operatorname{aac}\left(6^{\prime}\right)-1 e-a p h\left(2^{\prime \prime}\right)-1 a$ gene } & \multirow[t]{2}{*}{ Total } & \multirow[t]{2}{*}{$\mathbf{P}$} \\
\hline & & Positive, N (\%) & Negative, N (\%) & & \\
\hline HLSR & $\mathrm{R}$ & $47(74.6)$ & $16(25.4)$ & $63(100)$ & $<0.001$ \\
\hline & S & $11(29.7)$ & $26(70.3)$ & $37(100)$ & \\
\hline HLGR & $\begin{array}{l}\text { R } \\
\text { S }\end{array}$ & $\begin{array}{c}40(100) \\
18(30)\end{array}$ & $\begin{array}{c}0(0) \\
42(70)\end{array}$ & $\begin{array}{l}40(100) \\
60(100)\end{array}$ & $<0.001$ \\
\hline
\end{tabular}

R, resistant; S, susceptible. 
determined vancomycin resistance in rate of $3.9 \%$ by GDM in Sweden, Paberzo and colleagues determined $20 \%$ by GDM in Lithuania, Udo and colleagues determined $3 \%$ by GDM in Kuwait. ${ }^{26-28}$

VanA and VanB are the most common resistance genotypes, although there are seven different glycopeptide resistant genotypes found in enterococci. In United States and Europe VanA resistance phenotype is more common than others. ${ }^{29,30}$ When compared with other types of enterococci, VanA resistance phenotype occurs more frequently. In our study, VanA type resistance have been identified in five of strains by PCR. All of these five strains were $E$. faecium. First time in Turkey VanA phenotypes of $E$. faecium was isolated in 2001.31 Then, in 2002 , outbreak of VanA phenotype $E$. faecium was reported. ${ }^{32}$ Coskun and colleagues identified VanA and VanB genes in thirty and five strains respectively. ${ }^{33}$ These are the first VanB positive $E$. faecium strains in our country. And also Kirdar and colleagues also found VanA gene in 12 vancomycin resistant $E$. faecium isolated from patients with hematologic malignancies. ${ }^{19}$ In a study in 2000 with the participation of our country, the prevalence of vanA VRE was found highest in the United Kingdom (2.7\%), while the prevalence of vanB VRE was highest in Slovenia (2\%). ${ }^{34}$ The prevalence of VanC VRE was highest in Latvia and Turkey, where rates were 14.3 and $11.7 \%$, respectively. The highest prevalence of high-level gentamicin-resistant enterococci was seen in Turkey and Greece. ${ }^{34}$

Contrast to VanA type, which is common worldwide, VanB type is much less frequently encountered but VanB type have been reported from different countries. ${ }^{35}$ Nelson and colleagues found that seven $E$. faecalis strains have VanA phenotype in their study, which includes vancomycin resistant 144 (93.5\%) $E$. faecium, seven (4.5\%) E. faecalis and three (2\%) E. gallinarum. ${ }^{36}$ It was determined that remaining six strains have VanA phenotype and 138 of 144 E. faecium have VanB phenotype. Van $C$ - 1 gene was amplified in one of three $E$. gallinarum strains. Descheemaeker and colleagues reported that $46.1 \%$ of 601 vancomycin resistant strains was carrying VanA gene while enterococci carrying $\operatorname{Van} B$ gene were not detected. ${ }^{30}$

Low-level aminoglycoside resistance in enterococci, due to a reduction of the permeability of the cell wall. The high-level resistance is mediated by ribosomal or inactivating enzymes. A synergistic beta-lactam-aminoglycoside bactericidal effect is eliminated in the presence of high-level aminoglycoside resistance. High-level aminoglycoside-resistant enterococci are important because they can be resistant to other antibiotics. In our study HLGR rate was $40 \%$, HLSR rate was determined as $63 \%$. No difference was found between Enterococcus species according to HLGR and HLSR rates. High-level aminoglycoside resistance rate was repoted as $16 \%$ in the study from our country. ${ }^{11}$ Sirin and Adiloglu also reported HLGR and HLSR rate as 23 and 16\% respectively. ${ }^{19}$ Another two studies HLAR rates were reported as 39.7 and $54.5 \%$ in $E$. faecalis, 9.1 and $36.3 \%$ in $E$. faecium. ${ }^{11,18}$ HLAR rate was reported $48.1 \%$ in Turkey by European vancomycin-resistant enterococci study group. ${ }^{34}$ HLGR rate was reported in a range $5-65 \%$, HLSR rate was reported in a range $14-50.4 \%$ in the studies from other contries. ${ }^{13,14,37-39}$

The addition of aminoglycoside to an antibiotic, which inhibits cell wall synthesis, plays a significant role in increasing effect of both drugs. However acquired genes through plasmid and transposon lead to release aminoglycosides modifying enzymes and high level aminoglycosides resistance. Thus, the combination treatment loses its synergistic effect. ${ }^{4,5}$ The most common aminoglycoside modifying enzymes in enterococci is APH (2")-AAC (6 ') enzyme, which is consisting of two enzymes and responsible for resistance to all aminoglycosides except streptomycin. ${ }^{4}$ aac $\left(6^{\prime}\right)-I e$ aph(2")-Ia gene, which encoding bifunctional aac (6')-Ie-aph (2")-Ia enzyme is the most common clinically.

Aminoglycoside-modifying enzymes are the responsible from high-level streptomycin resistance. ${ }^{5,6}$ Aminoglycoside-modifying enzyme encoding aminoglycoside resistance genes found so far in Enterococcus are $\operatorname{aac}\left(6^{\prime}\right)-I e-\operatorname{aph}\left(2^{\prime \prime}\right)-I a, a p h\left(2^{\prime \prime}\right)-I b, a p h\left(2^{\prime \prime}\right)-I c$, $\operatorname{aph}\left(2^{\prime \prime}\right)-I d$, aph(3')-IIIa, aac(6')-Ii, ant(3”)Ia, ant( $\left.4^{\prime}\right)-I a$, ant $\left(6^{\prime}\right)-I a .^{5-7}$ In our study, aac $\left(6^{\prime}\right)$-1e-aph (2')-1a gene was identified in 58 (58\%) strains. In no strains aph (2")-1b, aph (2")- $1 c$ and aph (2")-1d genes were detected. Feizabadi and colleagues found that $\operatorname{aac}\left(6^{\prime}\right)$ $1 e$-aph(2")-1a gene was detected in 59 strains of 114 enteroocci strains and aph (2")-Ic gene was detected in $2 E$. faecium strains by PCR in their study. ${ }^{37}$ Similar to our study, none of aph (2")- $1 b$ and $a p h$ (2")- $1 d$ gene were not detected. In a study conducted by 279 enterococci strains obtained at a university hospital in Japan, aac (6 ')-1e-aph (2')-1b gene was found to be more than E. faecium (4.3\%) compared with $E$. faecalis (42.5\%). aph (2")-Ic gene was not detected in the strains of any enterococci. ${ }^{40}$

In recent years, the emergence of enterococci strains, which cause increasing frequency infections, has significantly restricted antibiotics used to treat infections. Glycopeptides are the most effective agents against enterococci. However, the unnecessary utilization will result increasing the frequency of glycopeptide-resistant enterococci and treatment impasse. Another problem encountered in the treatment of enterococcal infections is HLAR.
Treatment options are limited in high-level aminoglycoside-resistant enterococci because of disappeared beta-lactam-aminoglycoside combination for synergistic bactericidal effect. For these reasons, accurate identification of enterococci, determination of antimicrobial resistance state in time, a different resistance pattern and to reveal the resistance mechanisms is important.

\section{References}

1. Mundy L, Sahm D, Gilmore M. Relationships between enterococcal virulence and antimicrobial resistance. Clin Microbiol Rev 2000;13:513-22.

2. Sood S, Malhotra M, Das B, Kapil A. Enterococcal infections \& antimicrobial resistance. Indian J Med Res 2008;128: 111-21.

3. Lefort A, Mainardi J, Tod M, Lortholary 0. Antienterococcal antibiotics. Med Clin North Am 2000;84:1471-95.

4. Shepard B, Gilmore M. Antibiotic resistant enterococci: the mechanisms and dynamics of drug introduction and resistance. Microbes Infect 2002;4:215-24.

5. Patterson J. New gram-positive agents in nosocomial infection. Curr Opin Infect Dis 2000;13:593-8.

6. Uttley A, Collins C, Naidoo J, George R. Vancomycin-resistant enterococci. Lancet 1988;1:57-8.

7. Boyd D, Willey B, Fawcett D, et al. Molecular characterization of Enterococcus faecalis N06-0364 with lowlevel vancomycin resistance harboring a novel D-Ala-D-Ser gene cluster, vanL. Antimicrob Agents Chemother 2008;52:2667-72.

8. Clinical and Laboratory Standards Institute (CLSI). Performance Standards for Antimikrobial Susceptibility Testing; Twenty-Third Informational Supplement. Wayne, PA: CLSI Document M100-S23; 2013.

9. Aktas Z, Diyarbakirli P, Bal C, et al. Investigation of phenotypic and genotypic characteristics of vancomycin-resistant Enterococcus faecium isolates. Mikrobiyol Bul 2003;41:347-56.

10. Qu T, Chen Y, Yu Y, et al. Genotypic diversity and epidemiology of high-level gentamicin resistant Enterococcus in a Chinese hospital. J Infect 2006;52:124-30.

11. Kacmaz B, Aksoy A. Antimicrobial resistance of enterococci in Turkey. Int $\mathrm{J}$ Antimicrob Agents 2005;25:535-8.

12. Tatman-Otkun M, Gürcan S, Ozer B, et al. Antibiotic resistance among enterococci isolated from clinical samples at Trakya University Hospital in the last two years. 
Mikrobiyol Bul 2005;39:133-5.

13. Moaddab S, Rafi A. Prevalence of vancomycin and high level aminoglycoside resistant enterococci among high-risk patients. Southeast Asian J Trop Med Public Health 2003;34:849-54.

14. Mirovi V. Antibiotic resistance in hospital strains of Enterococcus faecalis and Enterococcus faecium. Vojnosanit Pregl 2002;59:499-506.

15. d'Azevedo P, Dias C, Teixeira L. Genetic diversity and antimicrobial resistance of enterococcal isolates from Southern region of Brazil. Rev Inst Med Trop Sao Paulo 2006;48:11-6.

16. Akhter S, Asna Z, Rahman, M. Prevalence and antimicrobial susceptibility of enterococcus species isolated from clinical specimens. Mymensingh Med J 2011;20:694-9.

17. Yildirim M, Sencan I, Ozdemir D, et al. Vancomycin and high-level aminoglycoside resistant Enterococcus carriage and the risk factors related to resistance in hospitalized patients. Mikrobiyol Bul 2007;41:271-7.

18. Sirin M, Adiloglu A. Comparison of five antimicrobial susceptibility tests in detecting high level aminoglycoside and vancomycin resistances in hospital acquired Enterococcus isolates. Clin Lab 2011;57:157-62.

19. Kirdar S, Sener A, Arslan U, Yurtsever S. Molecular epidemiology of vancomycinresistant Enterococcus faecium strains isolated from haematological malignancy patients in a research hospital in Turkey. $\mathrm{J}$ Med Microbiol 2010;59:660-4.

20. Comert F, Kulah C, Aktas E, et al. First isolation of vancomycin-resistant enteroccoci and spread of a single clone in a university hospital in northwestern Turkey. Eur J Clin Microbiol Infect Dis 2007;26:57-61.

21. Ak S, Koroglu M, Ak M. The evaluation of antimicrobial susceptibility of urine enterococci with the Vitek 2 automated system in eastern Turkey. Southeast Asian J Trop
Med Public Health 2012;43:986-91.

22. Protonotariou E, Dimitroulia E, Pournaras $\mathrm{S}$, et al. Trends in antimicrobial resistance of clinical isolates of Enterococcus faecalis and Enterococcus faecium in Greece between 2002 and 2007. J Hosp Infect 2010;75:225-7.

23. Efe Iris N, Sayıner H, Yildirmak T, et al. Vancomycin-resistant enterococcus carrier status in the reanimation units and related risk factors. Am J Infect Control 2013;41:261-2.

24. Karaca Y, Pullukçu H, Aydemir S, et al. Antibiotic susceptibility and beta lactamase activity of enterococci isolates. Clin Microbiol Infect 2001;7:1-394.

25. Zouain M, Araj G. Antimicrobial resistance of Enterococci in Lebanon. Int $\mathrm{J}$ Antimicrob Agents 2001;17:209-13.

26. Hallgren D, Hanberger H, Hossain A, et al. Activity of common and new antimicrobial agents against enterococci at intensive care units in Sweden. Clin Microbiol Infect 2000;6:127.

27. Paberzo R, Majore A, Luzbinska L, Hromova S. Invitro resistance of antibiotic against gram positive cocci in Latvia. Clin Microbiol Infect 2000;6:104.

28. Udo E, Al-Sweish N, John $\mathrm{P}$, et al. Antibiotic resistance patterns of enterococci isolated in Kuwait Hospitals. Clin Microbiol Infect 2001;7:1-394.

29. Moellering RJ. Vancomycin-resistant enterococci. Clin Infect Dis 1998;26:1196-9.

30. Descheemaeker P, Leven M, Chapelle S, et al. Prevalence and molecular epidemiology of glycopeptide-resistant enterococci in Belgian renal dialysis units. J Infect Dis 2000;181:235-41.

31. Basustaoglu A, Aydogan H, Beyan C, et al. First glycopeptide-resistant Enterococcus faecium isolate from blood culture in Ankara, Turkey. Emerg Infect Dis 2001;7:160-1.

32. Colak D, Naas T, Gunseren F, et al. First outbreak of vancomycin-resistant entero- cocci in a tertiary hospital in Turkey. $\mathrm{J}$ Antimicrob Chemother 2002;50:397-401.

33. Coskun F, Mumcuo lu I, Aksu N, et al. Phenotypic and genotypic traits of vancomycin-resistant enterococci in a public hospital: the first vanB-positive Enterococcus faecium isolates. Mikrobiyol Bul 2012;46:276-82.

34. Schouten M, Hoogkamp-Korstanje J, Meis $\mathrm{J}$, et al. Prevalence of vancomycin-resistant enterococci in Europe. Eur J Clin Microbiol Infect Dis 2000;19:816-22.

35. Werner G, Coque T, Hammerum A, et al. Emergence and spread of vancomycin resistance among enterococci in Europe. Euro Surveill 2008;13:19046.

36. Nelson R, McGregor K, Brown A, et al. Isolation and characterization of glycopeptide-resistant enterococci from hospitalized patients over a 30 -month period. J Clin Microbiol 2000;38:2112-6.

37. Feizabadi M, Maleknejad P, Asgharzadeh A, et al. Prevalence of aminoglycosidemodifying enzymes genes among isolates of Enterococcus faecalis and Enterococcus faecium in Iran. Microb Drug Resist 2006;12:265-8.

38. Miranda G, Lee L, Kelly C, et al. Antimicrobial resistance from Enterococci in a pediatric hospital. Plasmids in Enterococcus faecalis isolates with highlevel gentamicin and streptomycin resistance. Arch Med Res 2001;32:159-63.

39. Del Campo R, Tenorio C, Rubio C, et al. Aminoglycoside-modifying enzymes in high-level streptomycin and gentamicin resistant Enterococcus spp. in Spain. Int J Antimicrob Agents 2000;15:221-6.

40. Kobayashi N, Alam M, Nishimoto Y, et al. Distribution of aminoglycoside resistance genes in recent clinical isolates of Enterococcus faecalis, Enterococcus faecium and Enterococcus avium. Epidemiol Infect 2001;126:197-204. 